\section{Advocacy and coverage of needle exchange programs: results of a comparative study of harm reduction programs in Brazil, Bangladesh, Belarus, Ukraine, Russian Federation, and China}

\author{
Advocacy e cobertura de projetos de troca \\ de agulhas: resultados de um estudo \\ comparativo sobre programas de redução \\ de danos no Brasil, Bangladesh, Belarus, \\ Ucrânia, Federação Russa e China
}

Dave Burrows 1

\title{
Background
}

1 AIDS Projects Management Group, Sydney, Australia.

Correspondence

D. Burrows

AIDS Projects Management Group. Level 2, 50 York St. Sydney 2000 Australia. dave@aidsprojects.com

\begin{abstract}
To prevent or mitigate an AIDS epidemic among injecting drug users (IDUs), effective activities need to be implemented on a large enough scale to reach and assist sufficient numbers of drug users and thereby change their risk behaviors related to drug use and sex. Recent work by UNAIDS on "high coverage sites", adopting the above strategies, has shown that one of the key elements in achieving high coverage is ongoing and sophisticated advocacy. High coverage harm reduction sites were studied through literature search and site visits, including key informant interviews, review of service statistics, and data analysis, in order to document the steps that led to scaling up, the way coverage was defined in these sites, and the lessons learned from their efforts. Syringe-exchange programs can achieve high coverage of IDUs. Monitoring to determine regular reach (those who are in regular contact with harm reduction services) should be added to uniform data collection carried out by harm reduction programs. Advocacy is crucial to achieving high coverage.
\end{abstract}

Syringe-Exchange Programs; Intravenous Substance Abuse; Acquired Immunodeficiency Syndrome; Harm Reduction
The twin epidemics of injecting drug use and AIDS linked to sharing of injection equipment have already had a major impact on the health, social, and economic well-being in many countries and regions. By mid 2005, these epidemics had occurred in North and South America, Western, Central and Eastern Europe, Southeast and South Asia, and were beginning in the Middle East and in Africa 1.

While explosive epidemics have been occurring among injecting drug users (IDUs) in many different areas, there is evidence that AIDS epidemics among IDUs can be prevented, slowed, stopped, and even reversed. For example, all Australian cities 2, Hong Kong (People's Republic of China) 3, and Dhaka (Bangladesh) 4 have maintained HIV prevalence among IDUs at less than $5 \%$; the epidemic among IDUs in Nepal appears to have been delayed for several years 5; and HIV prevalence among IDUs in New York City 6 and several Brazilian cities 7 has fallen. All of these changes appear to have been caused by a range of specific activities which form an effective approach to addressing AIDS among IDUs.

By 2000, the international community had reached a consensus on the composition of these effective approaches. In Preventing the Transmission of HIV Among Drug Abusers: A Position Paper of the United Nations System 8 , 
the United Nations (UN) agencies together with the World Health Organization (WHO) and other international agencies agreed that action was urgently needed to implement the following activities to address HIV/AIDS among IDUs: - Drug abuse treatment, in particular drug substitution treatment such as methadone maintenance, therapeutic communities, and outpatient drug-free programs, assist IDUs to decrease their drug consumption significantly. - Outreach activities have been successful in accessing, motivating, and supporting IDUs who are not in treatment to reduce their illicit drug use risk behaviors and sexual risk behaviors as well as reducing HIV incidence. Findings from research indicate that outreach activities that take place outside the conventional health and social care environments reach out-of-treatment drug injectors and increase drug treatment referrals.

- Syringe and needle exchange programs have shown reductions in needle risk behaviors and HIV transmission and no evidence of increased injecting drug use or other public health dangers in the communities served. Such programs also serve as points of contact between IDUs and service providers, including drug treatment programs. The benefits of such programs increase considerably if they go beyond syringe exchange alone to include AIDS education, counseling, and referral to a variety of treatment options.

To prevent or mitigate an AIDS epidemic among IDUs, the above activities need to be implemented on a large enough scale to reach and assist sufficient numbers of drug users to change their risk behaviors related to drug use and sex. This has been achieved in many cities in North America, Western Europe, and Australasia and even in entire countries such as the United Kingdom, Netherlands, Germany, and Australia.

Increasingly, the importance of coverage of programs to prevent HIV infection among IDUs is being discussed in developing and transitional countries. For example, in 1999, at the first Eastern European Regional HIV Strategy Meeting 9 , a coverage target of $60 \%$ was accepted by a range of agencies working on the prevention of HIV among IDUs (among them WHO and The Joint United Nations Programme on HIV/AIDS - UNAIDS), but little work has been done to determine how to operationalize this target.

Recent work by UNAIDS on "high coverage sites" adopting the above strategies has shown that one of the key elements in achieving high coverage is ongoing and sophisticated advocacy.

\section{Methods}

In 2002, UNAIDS commissioned an investigation 10 of sites in developing and transitional countries which were regarded by international authorities as "high coverage sites" to examine the issue of coverage of injecting drug users "in the field". To determine which sites should be investigated, a survey was conducted by email of 20 of the world's leading consultants working in developing and transitional countries on harm reduction. Only sites mentioned by more than one consultant were considered. In all, six sites were chosen by UNAIDS. These were:

- Eastern Europe: Soligorsk, Belarus; Pskov, Russian Federation; and Sumi, Ukraine.

- Asia: Dhaka, Bangladesh.

- Latin America: Salvador and Porto Alegre, Brazil.

In the course of carrying out the investigation, Rajshahi (Bangladesh) was added to this list, as was Hong Kong (People's Republic of China), which is included due to the high coverage of its main approach (methadone maintenance treatment). Due to problems with data collection, Porto Alegre was excluded from the study. It should be noted that the list of sites selected for study in this report is not an exhaustive list of high coverage sites.

The author was contracted to investigate how projects in these sites had succeeded in scaling up services to achieve "high coverage", to define the coverage of each site's HIV prevention services among IDUs, and to determine what factors are common to their success. The final objective was to document the steps that led to scaling up, the way coverage was defined in these sites, and the lessons learned from their efforts.

A literature search was conducted using published papers about the sites under investigation. Consultations were held with key researchers working on issues related to coverage of HIV prevention activities among IDUs. These efforts resulted in several data sources which were used to triangulate data from service statistics (for the sites), and discussions with authors of scientific papers (published or in progress) about their findings related to coverage (in both developed and less developed settings). Site visits were made to most "high coverage sites" where methods included key informant interviews, review of service statistics, examination of monitoring methods and forms, and analysis of data to determine coverage levels. 


\section{Definitions}

There are three sets of measures that may provide information about coverage of IDUs by HIV prevention services, of which two are used in this paper. Each measure uses as a base the estimated size of the IDUs population in a given locality. Due to the hidden nature of injection drug use in most cultures, such an estimate is difficult to make.

For the first two measures, the concept of reach is important: "injecting drug users reached" refers to those IDUs contacted by any agency with procedures or materials known to be effective in HIV prevention among IDUs, such as sterile needles and syringes, substitute drug treatments (methadone or other), or abstinence-based drug treatment and rehabilitation (excluding detoxification, which is not regarded as an effective treatment on its own). Interventions providing these services are referred to in the text as needle-syringe programs, substitution treatment programs, and drug rehabilitation programs, respectively.

One important figure is the number of injecting drug users ever contacted by a service: the "ever reached" figure. This figure is cumulative and continues for as long as the service continues in operation (thus, a service can theoretically achieve a $100 \%$ ever-reached figure by contacting every individual injecting drug user in a specified geographic area). In practice, figures of $100 \%$ are rarely, if ever, achieved (due to changes in modes of drug use, new injectors, etc). To calculate this figure, services need to have a way of identifying all IDUs.

A second measure is regularity of access to a service. This is called "regular reach" in this paper. It is a difficult measure, as there are many different ways of measuring "regularity". In the UNAIDS report, the monitoring results provided by each service or set of services were analyzed to try to determine a "regular reach" figure. Due to the diversity of monitoring methods employed, comparability is difficult between sites.

The third measure is defined as "the number of sterile syringes provided to injecting drug users divided by the estimated number of injections during a specified time frame". This is a complex measure with so many possible errors (for example, in calculating the number of IDUs, the number of injections per IDU, the number of syringes available from a variety of sources), that this measure is generally not used in this paper (Table 1).

\section{Results}

The following features were found to be common to the high coverage programs studied: (1) harm reduction principles used to develop programs suited to the context; (2) prioritized, staffed, and funded advocacy; (3) support from the general community and its government representatives, religious leaders, and other opinion leaders; (4) a crucial role for law enforcement; (5) funding that facilitated expansion to achieve high coverage; (6) sustained funding; (7) context-appropriate differences in ways of approaching injecting drug users and the services most likely to attract them to a program; (8) replication of a single program to address IDUs in other districts, cities, provinces; (9) convenience of access; (10) involvement of

Table 1

"High coverage" sites with effective HIV prevention among IDUs.

\begin{tabular}{|c|c|c|c|c|c|c|}
\hline Site & Country & $\begin{array}{l}\text { Population } \\
(x 1,000)\end{array}$ & IDUs (n) & $\begin{array}{c}\text { Ever } \\
\text { reached (\%) }\end{array}$ & $\begin{array}{l}\text { Regular reach } \\
\text { in } 1 \text { month (\%) }\end{array}$ & $\begin{array}{c}\text { HIV prevalence/ } \\
\text { IDUs (\%) }\end{array}$ \\
\hline Soligorsk & Belarus & 100 & 1,370 & 94.0 & 14.0 & 20.0 \\
\hline Pskov & Russian Federation & 206 & 1,250 & 92.0 & 14.0 & $5.0^{*}$ \\
\hline Sumy & Ukraine & 297 & 1,500 & 73.0 & 23.0 & $<5.0$ \\
\hline Dhaka & Bangladesh & 12,000 & 7,650 & 100.0 & 52.0 & $4.0 * \star$ \\
\hline Rajshahi & Bangladesh & 300 & 885 & 56.0 & 49.0 & $0.0^{\star \star}$ \\
\hline Hong Kong & China & 6,800 & 6,547 & 87.0 & 60.0 & $<2.0^{\star \star \star}$ \\
\hline Salvador & Brazil & 3,000 & 9,500 & 68.0 & 7.0 & Not available \\
\hline
\end{tabular}

Note: All figures from UNAIDS 10, except those referenced below.

* AIDS Foundation East West/Russian Federation Ministry of Health 14

** Bangladesh AIDS/STD Control Programme 15 .

*** Xinhua News Agency 3 . 
IDUs; (11) management issues; and (12) learning from experience.

Harm reduction principles used to develop programs suited to the context

The sites studied are located in a wide range of social, political, religious and cultural contexts. In Russian Orthodox cities like Pskov, Islamic cities in Bangladesh, and largely Catholic Brazil; in industrial and financial services economies and those based on agriculture; in cities like Dhaka with 12 million people and small towns of 30,000; in transitional countries and longstanding democracies; programs have reached a high coverage among IDUs.

The specific features of each program studied are unique to the social, political and cultural context in which they have been implemented. This has led to differences in methods of operation, numbers and types of staff, specific services and products provided, links with other services, and so on. Rather than impose models developed from other countries, program planners and implementers have studied principles of effective interventions and designed appropriate HIV interventions for their sites.

\section{Prioritized, staffed, and funded advocacy}

Effective approaches for addressing HIV/AIDS among injecting drug users are controversial in many parts of the world. In each site, careful thought and substantial work was devoted to overcoming community fears and government concerns about the proposed programs. In several sites, at least part of the work of several salaried workers was devoted to advocacy. In some cases, such as in Dhaka and Rajshahi, specific staff positions were dedicated to advocacy.

In addition, each of the programs involved at least one person who could be called a "credible proponent". A credible proponent is a person or organization proposing effective approaches who will be listened to and has authority with the government and, if possible, with the general community. Credible proponents normally have or can quickly make links with senior government officials, both within the health field and in other key sectors such as administration and law enforcement.
Support from the general community and its government representatives, religious leaders, and other opinion leaders

This was generally achieved through advocacy at many levels (including with the community in the immediate neighborhood of services), formal and informal meetings, public information campaigns, involvement by program managers in multi-sectoral AIDS and drugs committees and, in most cases, by a careful building of relationships with selected representatives from mass media. In addition, regular evaluations and dissemination of evaluation results helped to build political and community support. In some cases, political support translated into policies and laws which call for specific HIV services to be provided and government funding to ensure that programs are implemented.

\section{A crucial role for law enforcement}

Effectively addressing HIV/AIDS among IDUs in most countries means that programs are implemented in a criminal milieu. Effective programs need to go where drug users are, working with drug dealers and shooting gallery owners, to ensure that the maximum number of IDUs participate in the program. Outreach workers carrying new and used needles and syringes need to do their work without having supplies confiscated. Clients need to attend needle exchange sites and methadone or HIV treatment clinics without fear of arrest. Law enforcement does not have to support every activity of effective programs but, to achieve high coverage, it must allow such programs to do their work without hindrance.

At the least, law enforcement in most of the sites studied entered into flexible and trustful working relationships with program staff. At its greatest extent, law enforcement was involved as a full partner in planning and expanding programs. In most sites studied, senior law enforcement staff were consulted from the very beginning of the planning process and regularly throughout implementation.

\section{Funding that facilitated expansion to achieve high coverage}

All programs except that in Hong Kong were started with external donor funding. The most likely reason that most of the sites described in Eastern Europe are cities with IDUs populations of $1,000-1,500$ is that HIV programs in such cities are more likely to fit within the usu- 
al range of donor funding for HIV prevention programs among IDUs in that region (usually US $\$ 20,000-\$ 30,000$ per year). In places with larger numbers of IDUs, such as Dhaka and Hong Kong, much higher investment has been needed. Staff at CARE Bangladesh spoke specifically of the flexibility of the donor's approach as a factor in achieving high coverage in Dhaka. In Hong Kong, government commitment to funding methadone treatment for all opiate users who need it led to very high coverage. In all other sites, funding increased in at least the early years of the programs to take account of rising use of services.

\section{Sustained funding}

None of the programs described here reached high coverage in 12 months, yet that is often the length of external funding contracts. In most cases, it took more than three years to achieve high coverage. With the exception of the Soligorsk and Brazilian programs, funding increased each year. In programs where funding had reduced, the breadth of services had generally decreased and coverage was likely to suffer as a result.

\section{Context-appropriate differences}

in ways of approaching injecting drug

users and the services most likely

to attract them to a program

All programs described in the case studies offered a range of services in addition to needle exchange or methadone (Table 2): in many cases, breadth of service was achieved through close links and partnerships with other organizations. This breadth of services is likely to attract a wide range of IDUs, including users of various drugs, males and females, younger and older people, and people of different ethnicities. In addition, people at risk of HIV infection linked with drug use may include people who do not inject drugs. Some programs have needed to work with sexual partners of IDUs, with sex workers (who may also inject drugs), with families of drug users, and with non-injecting users who may switch to injecting at some point.

Replication of a single program

to address injecting drug users

in other districts, cities, provinces

As the CARE process in Bangladesh showed, successful HIV prevention programs among IDUs can be started at one site, taken to scale, then replicated in other parts of the country. As the case studies showed in Belarus, Russian Federation, Ukraine, and Brazil, high coverage can also be achieved by several HIV prevention programs being started at the same time.

\section{Convenience of access}

In every case study, IDUs could access services in a variety of ways and at various times. Outreach had been the most common method of providing convenient access to education, needle and syringe exchange, and other services, while easy access to services for IDUs in fixed sites (near entrances, for example, or separate entrances for IDUs) have increased the attractiveness of services. For needle-syringe programs, the use of secondary exchange increased this convenience as IDUs can acquire injecting equipment through friends, drug dealers, or at shooting galleries. As substitution treatment programs usually operate from fixedsite clinics (with few exceptions, such as backpack buprenorphine distribution in India and methadone buses in Germany and the Netherlands), the number and location of clinics is vital to ensure convenience. Hong Kong's program is an excellent example of a highly convenient program.

\section{Involvement of injecting drug users}

Most program managers interviewed gave credit to a specific IDU as the "father" of the program, seeing his involvement very early in operations as vital in reaching other IDUs. Even with the Hong Kong methadone program, clients were involved through surveys which led to changes in services. Regular interaction between IDUs and staff on the basis of friendliness and respect appears to be a necessary factor in achieving high coverage. Working with groups of active and ex-users has been undertaken in Salvador, Dhaka, and Rajshahi.

\section{Management issues}

Technical assistance and training for managers and training and retraining (or ongoing training) of staff, especially those working face-toface with IDUs, is crucial. Effective supervision and ability to deal with problems, regular team meetings, and ongoing training opportunities lead to stability of staff which attracts regular attendance by IDUs. Also, successful programs tend not to be "top-heavy": there are usually only a few management/supervisory positions compared to field staff (or clinic staff in Hong Kong). Even in Dhaka, 11 managers/supervi- 
Table 2

Services provided by high coverage sites.

\begin{tabular}{|c|c|c|c|c|c|c|c|}
\hline Product/Service & $\begin{array}{c}\text { Soligorsk } \\
\text { NSPs }\end{array}$ & Pskov NSPs & Sumy NSPs & $\begin{array}{c}\text { Dhaka } \\
\text { Outreach/ } \\
\text { DICs }\end{array}$ & $\begin{array}{c}\text { Rajshahi } \\
\text { Outreach/ } \\
\text { DICs }\end{array}$ & $\begin{array}{l}\text { Hong Kong } \\
\text { methadone } \\
\text { clinics }\end{array}$ & $\begin{array}{c}\text { Salvador } \\
\text { CETAD } \\
\text { services }\end{array}$ \\
\hline Needles and syringes distributed & $x$ & $x$ & $x$ & $x$ & $x$ & & $X^{\star}$ \\
\hline Needles and syringes returned & $x$ & $x$ & $x$ & $x$ & $x$ & & $x$ \\
\hline Needles and syringes disposal & $x$ & $x$ & $x$ & $x$ & $x$ & & $x$ \\
\hline Water for injection & $x$ & $x$ & & & & & $x$ \\
\hline Alcohol swabs & $x$ & $x$ & $x$ & $x$ & $x$ & & $x$ \\
\hline Disinfectant for syringe cleaning & & $x$ & $x$ & & & & $x$ \\
\hline Vitamins & $x$ & $x$ & $x$ & & & & \\
\hline Filters/cotton balls & $x$ & & $x$ & $x$ & $x$ & & \\
\hline Medications for hepatitis & $x$ & & $x$ & & & & \\
\hline Treatments for HIV/AIDS & Referred & $x$ & $x$ & & & Referred & Referred \\
\hline Drug prevention activities & & & & & & & $x$ \\
\hline Drug detoxification & Referred & Referred & $x$ & $x$ & $x$ & $x$ & Referred \\
\hline Substitution drug treatment & & & & & & $x$ & \\
\hline Drug rehabilitation & & & & Referred & $x$ & Referred & Referred \\
\hline Other medications & & & $x$ & $x$ & & $x$ & \\
\hline Condoms distributed & $x$ & $x$ & $x$ & $x$ & $x$ & $x$ & $x$ \\
\hline IEC ** distributed & $x$ & $x$ & $x$ & $x$ & $x$ & $x$ & $x$ \\
\hline Face-to-face individual education/advice & $x$ & $x$ & $x$ & $x$ & $x$ & $x$ & $x$ \\
\hline Group education & & & $x$ & $x$ & $x$ & $x$ & $x$ \\
\hline STD services & $x$ & Referred & Referred & $x$ & $x$ & Referred & Referred \\
\hline Counseling (general) & $x$ & $x$ & $x$ & $x$ & $x$ & $x$ & $x$ \\
\hline Counseling (drugs) & $x$ & Referred & $x$ & $x$ & $x$ & $x$ & $x$ \\
\hline Counseling (HIV/AIDS) & $x$ & x & $x$ & $x$ & $x$ & $x$ & $x$ \\
\hline Legal assistance & $x$ & & & & & Referred & \\
\hline Housing/welfare assistance & & & & & & $x$ & \\
\hline Drug user support groups & $x$ & & & $x$ & $x$ & $x$ & $x$ \\
\hline Ex-drug user support groups & $x$ & & & $x$ & $x$ & $x$ & \\
\hline HIV support groups & & & & Referred & & & \\
\hline
\end{tabular}

* CETAD also provides caps for mixing drugs and materials for making safer crack pipes.

** IEC: information, education and communication materials.

sors work with more than 50 paid peer outreach workers.

\section{Learning from experience}

In Salvador, a Paulo Freire quote is used to describe the Centro de Estudos e Terapia do Abuse de Drogas (CETAD) program: "we make the road by walking". Due to the great variability of contexts in which programs address HIV among IDUs, a process of trial and error is needed to develop the specific mix of program elements, staffing, and other features that will achieve high coverage. New ideas need to be implemented, evaluated, and expanded if they work, or adjusted or abandoned if they are ineffective. Also, as the Pskov case study shows, start- ing a program and then gaining knowledge of international and Russian-based experience helped the managers to reflect on the work they had already started and thereby improve it.

Despite the excellent results achieved by the programs studied, several problems related to advocacy remain: (1) higher coverage is needed for several interventions; (2) relationships between programs and law enforcement or military activities remain difficult; (3) the balance between HIV prevention and treatment expenditure is likely to be an important issue in sustainability; and (4) gender and sex issues remain unresolved. 
High coverage is needed for several interventions

One disturbing issue arising from this study is that none of the sites studied offered a full range of substitution drug treatments, other forms of drug treatment, outreach and needle exchange, and HIV treatment, care and support. In many countries, essential elements of a comprehensive approach are missing: these include access to adequate, affordable treatments for sexually transmitted infections and HIV/AIDS; and voluntary counseling and testing. Increased advocacy efforts are needed to expand the range of services to meet the needs of IDUs.

Relationships between programs and law enforcement or military activities remain difficult

Regular and ad hoc advocacy at many levels, with both law enforcement and other sectors of the community, needs to be built into all programs at all levels. It appears that more work is needed to educate staff from law enforcement and other sectors about the need for comprehensive programs and their role in addressing HIV among IDUs.

The balance between HIV prevention and treatment expenditure is likely to be an important issue in sustainability

Providing antiretroviral (ARV) and other HIV treatments can lead to large funding cuts for HIV prevention. While providing HIV treatments is an important component of a comprehensive approach to HIV/AIDS, removing funding for prevention only leads to higher numbers of people living with HIV/AIDS and ever-expanding HIV treatment expenditures. Advocacy for prevention programming during scale-up of ARV treatment programs is vital.

\section{Gender and sex issues remain unresolved}

Low levels of participation by female IDUs in most programs studied remains a cause for concern. Sexual transmission of HIV tends to be less emphasized by programs than transmission related to drug use. Links between HIV prevention programs among sex workers and IDUs are often weak. Advocacy may be needed to persuade decision-makers to provide sufficient funding to address the needs of female IDUs, and to address sexual HIV transmission among and from IDUs.
Finally, there is a lack of standard monitoring methods and reporting. Standard monitoring methods would make coverage measures easier to determine and enhance comparability between programs. Standardized monitoring would also assist advocacy efforts by enabling programs to demonstrate their true reach and effects, and to argue for increased funding and resources to address IDUs needs.

\section{Discussion}

The most important conclusion of this study is that effective activities to address AIDS among IDUs can be and are implemented at high coverage levels in developing and transitional countries. Programs such as needle and syringe exchange and methadone are reaching more than $50 \%$ of IDUs in the sites studied. HIV treatment, care, and support have also achieved high coverage of HIV-positive injecting drug users in Brazil and Hong Kong and may do so soon in Bangladesh.

In at least some sites, the high coverage achieved has led to HIV epidemics among injecting drug users being averted or delayed. In Bangladesh, Hong Kong, Sumy and Pskov, high prevalence of HIV among IDUs has been avoided despite very high prevalence in nearby countries or provinces with similar cultures and levels of injecting drug use. In Soligorsk, the needle-syringe program started after high HIV prevalence had been established so the effect is not as clear (and much higher, sustained coverage for several years will most likely be needed to show a reduction in the prevalence rate). In the Brazilian sites, massive changes to drug use patterns confuse the prevalence picture but it is likely that programs there have stabilised and reduced HIV prevalence among IDUs.

The findings from this study echo various findings and statements in recent years that a relationship exists between advocacy and effectively addressing AIDS among IDUs: for example, Burrows et al. 11; Burrows 12; WHO/UNAIDS/UNODC 13. But this study is unique in showing that in each high-coverage site studied, advocacy was one of the most important activities in achieving high coverage.

For example, in Salvador (Brazil), CETAD opened the first needle-syringe program (NSP) in that country in 1995 after a ruling the previous year by the Federal Council on Psychoactive Drugs that needle-syringe programs could be approved if they were associated with research projects. CETAD is a facility operated by the Universidade Federal da Bahia in Salvador 
that has investigated drug issues in the city since 1985. Through communication with researchers and others implementing HIV prevention programs in Europe and the Americas, CETAD staff had learned of needle exchange but were prevented by legal barriers from starting such a program until 1995. In March of that year, the Bahia State Government approved the establishment of a NSP through CETAD to address the problems of needle sharing and high HIV infection rates among IDUs discovered during the center's surveys of drug users in the city's poor neighborhoods.

Financial and technical support for the NSP was provided by the Bahia State Secretary of Health, and further support was gained by the participation of a CETAD representative on the State Council on Psychoactive Drugs - Bahia State Secretary of Justice and Human Rights. CETAD staff met with police officials and held seminars with police to explain the operations of the NSP and the principles of harm reduction. Newspapers wrote articles about the opening of the NSP and interviewed health professionals, religious representatives, and IDUs. For its first six months, CETAD staff answered a stream of questions from media representatives, aided by a media consultant. The main points made were that the rate of HIV among IDUs in Salvador was high and that NSPs had been shown in other countries to help save lives and did not cause increases in drug abuse.

Similarly, in Dhaka (Bangladesh), the SHAKTI injecting drug user project was started in May 1998 by CARE with a heavy emphasis on advocacy. The Dhaka program employs a technical coordinator, one administrative position, and four program officers (one each concentrating on enhancing outreach effectiveness, mobilization of current and ex-users to form self-help groups, and advocacy), and eight field trainers all of whom work from the CARE Bangladesh Dhaka office. The field trainers supervise the work of peer outreach/NSP workers and dropin centre staff and provide them with on-thejob training following their structured training programs; help peer outreach workers do group education; and regularly monitor IDUs behavior and needs through six-monthly interviews with random samples of clients. Field trainers check that drop-in centers are run properly and each trainer works with one peer outreach worker each day, checking that outreach education and monitoring tasks are completed correctly. Field trainers also carry out neighborhood advocacy, calling for assistance from the program officer (advocacy) when needed. Outreach crises such as harassment of peer out- reach workers by police or hoodlums are also dealt with by field trainers and program officers.

Senior program managers and staff of CARE Bangladesh agreed that an important factor in achieving high coverage in Dhaka was the provision of significant resources for everyday advocacy in the neighborhoods near drop-in centers and outreach sites. Advocacy was also carried out prior to and during implementation of the project with key government, religious, and community leaders, using an approach that avoided confrontation, instead finding ways to work with law enforcement to develop local solutions in each drug-using area that allow programs to work effectively. Advocacy with donors was also vital so that a flexible approach could be taken to development of programs. CARE used this same approach when it replicated the Dhaka project in Rajshahi, Chapai Nawabganj, and Char Narendrar.

In Pskov (Russian Federation), a key factor in increasing coverage was building understanding and partnership with key officials in the city, such as the head of Oblast (Province) Health Department, the head of OBNON (drugs police), and the head of GUIN (Prisons Department). A resolution which the city NSP sought and received from the provincial Vice-Governor to implement harm reduction programs allowed expansion into the neighboring towns of Opochka and Velikie Luki.

Further research is required to answer many questions arising from this study. We still do not know the answer to the question "how much is enough?". Future effectiveness studies should track the real increases and decreases in HIV prevalence rates among IDUs in sites where funding and commitment is received for achieving high coverage. Studies of scaled-up interventions currently planned or being implemented would assist our understanding of real-world examples and give clearer guidance about the level and mix of services needed to prevent or reduce AIDS epidemics among IDUs.

In addition, further work is needed to develop quality indicators for HIV prevention and care services among IDUs. From this report and other studies, it is clear that quality of services is an important factor in achieving high coverage. 


\section{Resumo}

Para prevenir ou mitigar uma epidemia de AIDS entre usuários de drogas injetáveis (UDI), atividades eficazes devem ser implementadas numa escala suficiente para atingir e ajudar um número suficiente de usuários e, portanto, modificar seus comportamentos de risco em relação ao uso de drogas e práticas sexuais. Um estudo recente do UNAIDS sobre "locais de cobertura alta", ao adotar as estratégias propostas acima, demonstrou que um dos elementos centrais para atingir uma cobertura alta é a advocacy permanente e bem-elaborada. Locais de redução de danos que apresentavam altas taxas de cobertura foram estudados através de uma revisão bibliográfica e visitas aos locais de maior cobertura, incluindo entrevistas com informantes principais, revisão de dados estatísticos dos serviços e análise de dados para poder documentar os passos que levaram à ampliação do alcance dos projetos, à definição da cobertura dos programas e às lições aprendidas. Os programas de redução de danos podem alcançar uma ampla cobertura de UDI. Além da coleta de dados rotineiros, os programas devem monitorar os projetos para definir o alcance sistemático (ou seja, dos UDI que estão em contato permanente com os serviços de redução de danos). A advocacy é fundamental para alcançar taxas de cobertura altas.

Programas de Troca de Seringas; Uso Indevido de Droga Parenterais; Síndrome da Imunodeficiência Adquirida; Redução de Danos

\section{References}

1. United Nations Office on Drugs and Crime. World drug report 2005. Vienna: United Nations Office on Drugs and Crime; 2005.

2. Australian Commonwealth Department of Health and Ageing. Return on investment in needle and syringe programs in Australia. Canberra: Australian Government; 2002.

3. HIV cases up $17 \%$ in HK. Xinhua News Agency 2005; Feb 23.

4. Burrows D, Beg M. Bangladesh: Successful harm reduction under threat. Harm Reduct J; in press.

5. Crofts N, Reid G, Deany P. Injecting drug use and HIV infection in Asia. AIDS 1998; 12 Suppl B:S6978.

6. Des Jarlais D. How much is good enough. Coverage of HIV prevention programs in New York City. In: Programme and Abstract Book of the 12th International Conference on Reduction of Drug Related Harm, Abstract Book. New Delhi: Joint United Nations Programme on HIV/AIDS; 2001.

7. Bastos FI, Pina MF, Szwarcwald CL. The social geography of HIV/AIDS among injection drug users in Brazil. Int J Drug Policy 2002; 13:137-44.

8. United Nations. Preventing the transmission of HIV among drug abusers: a position paper of the United Nations System. Geneva: United Nations; 2000.

9. Joint United Nations Programme on HIV/AIDS. Second strategy meeting to better coordinate regional support to national responses to HIV/AIDS in Central and Eastern Europe and Central Asia. Copenhagen: Joint United Nations Programme on HIV/AIDS; 2000.

10. Joint United Nations Programme on HIV/AIDS. UNAIDS high coverage sites. HIV prevention among injecting drug users in transitional and developing countries: case studies UNAIDS best practice series. Geneva: Joint United Nations Programme on HIV/AIDS; in press.
11. Burrows D, Dorabjee J, Wodak A. Advocacy for harm reduction: objectives, strategies and activities. In: Proceedings of Global Research Network Meeting on HIV Prevention in Drug-Using Populations. 3rd Annual Meeting Report. Washington DC: National Institute on Drug Abuse; 2001. p. 131-8.

12. Burrows D. The art of the possible: Intervention strategies in high and increasing concentrated HIV epidemics among injecting drug users. In: Proceedings of $4^{\text {th }}$ Meeting of Global Research Network on HIV Prevention in Drug-Using Populations. Washington DC: National Institutes on Drug Abuse; 2002. p. 45-9.

13. World Health Organization/Joint United Nations Programme on HIV/AIDS/United Nations Office on Drugs and Crime. Advocacy guide: HIV/AIDS prevention for injecting drug users. Geneva/Vienna: World Health Organization/Joint United Nations Programme on HIV/AIDS/United Nations Office on Drugs and Crime; 2004.

14. AIDS Foundation East West/Russian Federation Ministry of Health. Officially registered HIV cases by region of the Russian Federation. Moscow: AIDS Foundation East West; 2005.

15. Bangladesh AIDS/STD Control Programme. National sentinel sero-surveillance report. Dhaka: World Health Organization/Joint United Nations Programme on HIV/AIDS/United Nations Office on Drugs and Crime; 2002.

Submitted on $27 / \mathrm{Jul} / 2005$

Final version resubmitted on 16/Oct/2005

Approved on 19/Oct/2005 